\title{
Patterns and trajectories of gestational weight gain: a prospective cohort study
}

\author{
Megan Jarman PhD, Yan Yuan PhD, Mohammadreza Pakseresht MD PhD, Qian Shi MSc, \\ Paula J. Robson PhD, Rhonda C. Bell PhD; the Alberta Pregnancy Outcomes and Nutrition study team; \\ the ENRICH team
}

\section{Abstract}

Background: Gestational weight gain in excess of or below Health Canada's guidelines is known to increase the risk of adverse outcomes for both the woman and her baby. This study describes patterns and trajectories of total and rate of gestational weight gain in a large prospective cohort of pregnant women and adolescents in the Alberta Pregnancy Outcomes and Nutrition study.

Methods: We collected weight and height data for 1541 pregnant adolescents and women (mean age 31 years, < 27 weeks' gestation) recruited through advertisements and physicians' offices in Calgary and Edmonton between May 2009 and November 2012. Data were collected once during each trimester following enrolment and once at about 3 months post partum. The participants were categorized according to their prepregnancy body mass index (BMI) as underweight, of normal weight, overweight or obese. We calculated distributions of total and weekly rates of weight gain and determined trajectories of weight gain for each prepregnancy BMI category.

Results: Of the 1541 participants, 761 (49.4\%) exceeded Health Canada's guidelines for total gestational weight gain, and 272 $(17.6 \%)$ gained less weight than recommended. A total of $63(19.2 \%)$ and $38(23.6 \%)$ participants categorized as overweight or obese, respectively, exceeded the recommended upper limit by 5 to less than $10 \mathrm{~kg}$, and $53(16.2 \%)$ and $27(16.8 \%)$, respectively, exceeded the upper limit by at least $10 \mathrm{~kg}$. Ninety-five participants (30.3\%) in the overweight group and $59(39.6 \%)$ of those in the obese group gained weight at more than double the recommended rate between the second and third trimesters. The median weight gain for participants in the normal, overweight and obese categories had exceeded recommended upper limits by about 30,20 and 18 weeks' gestation, respectively.

Interpretation: Adherence to Health Canada's guidelines for gestational weight gain was low. Excess gestational weight gain was most marked among those with a prepregnancy BMI in the overweight or obese category. The findings suggest that weight management in pregnancy is challenging and complex. Messages and supports that are tailored for women in different prepregnancy BMI categories may help to improve guideline-concordant gestational weight gain.

\begin{abstract}
- nadequate or excessive weight gain during pregnancy increases the risk of adverse outcomes for the woman and her baby. Gaining too little weight has been associated with higher risk of the infant's dying ${ }^{1}$ and being small for gestational age. ${ }^{2}$ Gaining too much weight increases the risk of postpartum weight retention ${ }^{3}$ and cesarean delivery ${ }^{4}$ and may also increase the risk of gestational hypertension in the woman ${ }^{4}$ and her infant's being large for gestational age. ${ }^{5}$

In 2010, Health Canada adopted and disseminated updated guidelines for gestational weight gain that had been developed by the Institute of Medicine (Table 1)., ${ }^{6,7}$ These guidelines are intended to support physicians and clinicians who practise in the area of prenatal care by providing appropriate ranges for total and weekly rates of gestational weight gain, based on a woman's prepregnancy body mass index (BMI).

The impetus for revising the guidelines was growing recognition that excessive weight gain in pregnancy is becoming increasingly prevalent. Typically, women in developed coun-
\end{abstract}

tries who gain too much weight are likely to have entered pregnancy with a BMI that classifies them as overweight or obese. $^{8-11}$ However, more recent studies have shown that excessive gestational weight gain is also prevalent in women with a normal prepregnancy BMI and it also occurs in underweight women, albeit to a lesser extent. ${ }^{4,12,13}$ Most studies in this area have focused on total gestational weight gain, with little consideration given to the trajectory of weight gain during the course of the pregnancy. Furthermore, many studies have simply classified women into 3 categories - "below,"

Competing interests: None declared.

This article has been peer reviewed.

Correspondence to: Rhonda Bell, rhonda.bell@ualberta.ca

CMAJ Open 2016. DOI:10.9778/cmajo.20150132 


\begin{tabular}{|lcc|}
\hline \multicolumn{2}{|l|}{$\begin{array}{l}\text { Table 1: Ranges of total and weekly rate of gestational } \\
\text { weight gain according to Health Canada's } \\
\text { recommendations, }{ }^{6,7} \text { by prepregnancy BMI category }\end{array}$} \\
\hline $\begin{array}{l}\text { Prepregnancy BMI } \\
\text { category }\end{array}$ & $\begin{array}{c}\text { Total gestational } \\
\text { weight gain, kg }\end{array}$ & $\begin{array}{c}\text { Weekly rate of } \\
\text { gestational weight } \\
\text { gain, kg }\end{array}$ \\
\hline Underweight & $12.5-18$ & $0.44-0.58$ \\
\hline Normal weight & $11.5-16$ & $0.35-0.50$ \\
\hline Overweight & $7-11.5$ & $0.23-0.33$ \\
\hline Obese & $5-9$ & $0.17-0.27$ \\
\hline Note: BMI = body mass index. & \\
\hline
\end{tabular}

"met" or "above" guidelines - and few have described the distribution of weight gain within groups of women according to prepregnancy BMI category. It is clear that more comprehensive information on patterns of gestational weight gain is needed to help identify women who may be at risk of not meeting guidelines for gestational weight gain and to guide the development of more effective intervention strategies.

The objective of this study was to describe patterns of total and rate of gestational weight gain in a cohort of pregnant adolescents and women in Alberta relative to Health Canada's revised guidelines for gestational weight gain. ${ }^{6,7}$

\section{Methods}

\section{Study design and population}

The Alberta Pregnancy Outcomes and Nutrition (APrON) study is a prospective cohort study of adolescent girls and women and their infants during pregnancy and post partum. Details of participant recruitment and study protocols have been published elsewhere. ${ }^{14,15}$ In brief, participants were recruited through advertisements in the media and in physicians' offices in Calgary and Edmonton between May 2009 and November 2012. Eligibility criteria were age 16 years or more, literacy in English and duration of gestation less than 27 weeks. Participants who provided written informed consent were invited to attend a study centre in Calgary or Edmonton once during each trimester following enrolment and once at about 3 months post partum. Ethics approval for the APrON study was obtained from the Health Research Ethics Boards at the University of Alberta and the University of Calgary.

\section{Procedure}

On enrolment, participants completed questionnaires concerning prepregnancy weight, age, parity, marital status, ethnicity, family income and education. At each visit, trained staff measured the participant's weight to the nearest $0.01 \mathrm{~kg}$ (Health o Meter Professional 752KL medical scale) and height to the nearest $0.1 \mathrm{~cm}$ (HM200P Portstad portable stadiometer, Charder Electronic Co., Ltd.). We calculated prepregnancy BMI using self-reported prepregnancy weight and measured height. Participants were classified as underweight (BMI $<18.5 \mathrm{~kg} / \mathrm{m}^{2}$ ), of normal weight (BMI 18.5 to
$<25 \mathrm{~kg} / \mathrm{m}^{2}$ ), overweight (BMI 25 to $<30 \mathrm{~kg} / \mathrm{m}^{2}$ ) or obese $\left(B M I \geq 30 \mathrm{~kg} / \mathrm{m}^{2}\right)$. Self-reported highest weight during the pregnancy was recorded at the postpartum visit.

\section{Outcome measures}

We calculated weight change during the pregnancy as the difference between the self-reported prepregnancy weight and the measured weight at each visit. The total gestational weight gain was calculated by subtracting the prepregnancy weight from the highest weight during the pregnancy. In cases in which the participant did not report her highest weight or reported a weight that was lower than had been measured during the third trimester, we calculated total gestational weight gain using measured weight in the third trimester. The weekly average weight gain during the second and third trimesters was calculated by subtracting measured weight in the second trimester from measured weight in the third trimester and dividing by the number of intervening weeks. The data for participants with missing values for measured weight in the second or third trimester $(n=84)$ were excluded from this analysis.

\section{Statistical analysis}

Within each prepregnancy BMI group, participants were categorized as "below" if they gained less than the lower limit of the recommended amount of weight gain, "met" if they gained within the recommended weight range, or "above" if they exceeded the upper limit of the recommended amount of weight gain. We used information from the infant's birth record to identify infants who were small or large for gestational age. The former is defined as below the 10th percentile for gestational age, and large for gestational age is defined as above the 90th percentile for gestational age. We assessed the association between small for gestational age/large for gestational age and adherence to guidelines for gestational weight gain using the $\chi^{2}$ test.

Participants were also categorized as below, met or above according to their adherence to guidelines for average weekly rate of weight gain during the second and third trimesters. We calculated the distributions of total and weekly rate of weight gain by prepregnancy BMI category as well as the proportions of participants who were 5 to less than $10 \mathrm{~kg}, 10-15$ $\mathrm{kg}$ and more than $15 \mathrm{~kg}$ over the upper recommended limit for their prepregnancy BMI category. We used box plots to explore the trajectory of weight gain throughout pregnancy, with each box indicating the median and interquartile range of weight gain within the range of gestational ages. Cut-off points for gestational age were selected such that the range of time for each box was as small as possible but had a minimum of 16 observations per box. The guideline ranges were superimposed onto each box plot to facilitate comparisons between observed and recommended gestational weight gain trajectories.

\section{Results}

A total of 2189 women and adolescent girls were recruited to the APrON study. The median gestational age at the time of 
enrolment was 16.6 (interquartile range 14.0-20.6) weeks. Of the 2189 participants, 319 were excluded because their baby was not full term ( $\geq 37$ weeks' gestation), they did not have a singleton or live birth, or birth information was missing; 190 were excluded because of missing prepregnancy weight or height or both; 138 were excluded because of both missing weight in the third trimester and self-reported highest weight in the pregnancy; and 1 was excluded because of a data error. Thus, the data for 1541 participants (mean age 31.3 [SD 4.4] years [range 16-44 years]) who gave birth to a single live fullterm infant and had complete data for gestational weight gain and prepregnancy weight status were included in the analyses. The participants who were excluded did not differ in sociodemographic or health-related characteristics from those who were included (data not shown).

We performed sensitivity analyses to explore the utility of using self-reported prepregnancy weight to calculate BMI. We compared BMI derived from height and weight measured in 528 participants recruited during the first trimester with BMI for the same participants derived from measured height and self-reported prepregnancy weight. Almost all participants (72 [98.6\%]) categorized as obese with the use of self-reported weight were also categorized as obese when measured values were used to derive BMI. Classification into the overweight, normal-weight and underweight categories was accurate for 94 (86.2\%), 287 (86.5\%) and 10 (71.4\%) participants, respectively. Forty-three participants (13.0\%) categorized as being of normal weight and $12(11.0 \%)$ of those categorized as overweight when self-reported weight was used to derive BMI actually belonged to the next-higher weight category.

The participants were predominantly white (1241 [80.5\%]), had a partner at the time of study enrolment (1460 [94.7\%]) and had completed tertiary education (1058 [68.6\%)] (Table 2). Just over half (827 ([53.7\%]) were pregnant with their first child. About three-quarters (1152 [74.8\%]) were enrolled during their second trimester, and 1265 (82.1\%) came to all scheduled pre- and postpartum visits. Almost two-thirds (994 ([64.5\%]) were of normal weight before pregnancy, 58 (3.8\%) were underweight, $328(21.3 \%)$ were overweight, and 161 $(10.4 \%)$ were obese.

Of the 1541 participants, 761 (49.4\%) exceeded Health Canada's guidelines for total gestational weight gain. The values by prepregnancy BMI category were: underweight 16 (27.6\%), normal weight 401 (40.3\%), overweight $232(70.7 \%)$ and obese $112(69.6 \%)$. Weight gain lower than recommended was observed in 272 participants (17.6\%), $10(17.2 \%)$ in the underweight group, $219(22.0 \%)$ in the normal-weight group, $20(6.1 \%)$ in the overweight group and $23(14.3 \%)$ in the obese group. There was also evidence of weight loss, particularly in those in the obese group.

Within each prepregnancy BMI category, there was wide variation in total gestational weight gain (Figure 1). Two participants $(3.4 \%)$ in the underweight group and 31 $(31.1 \%)$ in the normal-weight group exceeded the recommended upper limit by at least $10 \mathrm{~kg}$. A gain $10-15 \mathrm{~kg}$ over the upper limit was observed in 41 (12.5\%) and $19(11.8 \%)$ participants in the overweight and obese groups, respec- tively, and a gain more than $15 \mathrm{~kg}$ above the upper limit was observed in $12(3.7 \%)$ and $8(5.0 \%)$ participants, respectively. Among the participants with complete data on infant sex, birth weight and gestational age at delivery $(n=1365)$, the numbers of participants in the under, met and above weight gain categories who had infants who were small for gestational age were $39(16.2 \%), 43(9.5 \%)$ and $50(7.4 \%)$, respectively $(p<0.001)$. The corresponding numbers for participants who had large-for-gestational-age babies were 6 $(2.5 \%), 17(3.8 \%)$ and $67(9.9 \%)(p<0.001)$.

The proportion of participants who exceeded the recommended average weekly rate of weight gain between the second and third trimesters was higher in the overweight $(88.2 \%[n=$ $277])$ and obese $(79.9 \%[n=119])$ groups than in the underweight $(34.5 \%[n=19])$ and normal-weight $(60.3 \%[n=566])$ groups (Figure 2). A total of 24 (2.6\%), 95 (30.3\%) and 59 (39.6\%) participants in the normal-weight, overweight and obese groups, respectively, gained weight at a rate that was more than double the upper recommended limit.

For the normal-weight and overweight groups, the median weight gain exceeded the recommended upper limit by about 30 weeks and 20 weeks of gestation, respectively (Figure 3 ). Just over half (43/83 [51.8\%]) of the participants in the obese group whose data contributed to the box plots had gained more weight than the recommended upper limit by 18 weeks. In all BMI groups, weight gain continued to rise until the end of pregnancy.

\section{Interpretation}

In this group of adolescent girls and women from Alberta, adherence to Health Canada's revised guidelines for gestational weight gain was low. Excess gestational weight gain was most marked among those with a prepregnancy BMI in the overweight or obese category, although $40.3 \%$ of those who entered pregnancy with a normal BMI also experienced excessive weight gain. Participants varied in the extent to which they exceeded the guidelines, with $16 \%$ of those who were overweight or obese before pregnancy exceeding their respective guidelines by $10 \mathrm{~kg}$ or more. In addition, weight gain trajectories for participants in the normal-weight and overweight categories were similar. The extent to which these similarities reflect physiologic effects, psychosociobehavioural effects or some combination of these should be topics for future research. Finally, over half of the participants in both the overweight and obese groups exceeded their respective guidelines by about 20 weeks' gestation.

Our estimates are consistent with those reported in recent studies in other Western countries where gestational weight gain is measured routinely. ${ }^{4,12,16-18}$ This highlights the universality of this issue across many countries and health care systems. Of note are the findings from a recent study of gestational weight gain in women of normal weight with low-risk pregnancies across 7 countries, in which the average weight gain was $13.7 \mathrm{~kg}$, which is consistent with our result $(15.5 \mathrm{~kg}) .{ }^{19}$

The magnitude of excessive weight gain in our study and the fact that $4 \%$ of participants in the obese category 
appeared to lose weight suggest that weight management in pregnancy is a challenging and complex issue for women and health care providers. ${ }^{20}$ In our study, participants who gained excessively were more likely to have a baby who was large for gestational age, which corroborates findings from other research. ${ }^{21-24}$ Pregnancies that result in large-for-gestationalage infants are more likely to result in delivery complications including cesarean delivery, neonatal hypoglycemia and

\begin{tabular}{|c|c|c|c|c|c|c|}
\hline \multirow[b]{2}{*}{ Characteristic } & \multicolumn{5}{|c|}{ Prepregnancy BMI category; no. (\%) of participants* } & \multirow[b]{2}{*}{$p$ valuet } \\
\hline & $\begin{array}{c}\text { Overall } \\
(n=1541)\end{array}$ & $\begin{array}{c}\text { Underweight } \\
(n=58) \dagger\end{array}$ & $\begin{array}{l}\text { Normal weight } \\
(n=994) \dagger\end{array}$ & $\begin{array}{l}\text { Overweight } \\
(n=328) \dagger\end{array}$ & $\begin{array}{c}\text { Obese } \\
(n=161) \dagger\end{array}$ & \\
\hline $\begin{array}{l}\text { Prepregnancy BMI, } \\
\text { mean } \pm \text { SD }\end{array}$ & - & $17.7 \pm 0.9$ & $21.8 \pm 1.7$ & $27.1 \pm 1.4$ & $34.5 \pm 4.2$ & \\
\hline Height, $\mathrm{cm}$, mean \pm SD & - & $167.2 \pm 6.9$ & $165.6 \pm 6.4$ & $166.1 \pm 6.2$ & $165.0 \pm 7.7$ & \\
\hline $\begin{array}{l}\text { Prepregnancy weight, } \\
\text { kg, mean } \pm \text { SD }\end{array}$ & - & $49.5 \pm 5.1$ & $59.9 \pm 6.5$ & $74.8 \pm 7.0$ & $94.0 \pm 13.6$ & \\
\hline $\begin{array}{l}\text { Gestational weight gain, } \\
\text { kg, mean } \pm \text { SD }\end{array}$ & - & $16.9 \pm 6.8$ & $15.5 \pm 5.3$ & $15.2 \pm 6.0$ & $12.3 \pm 7.8$ & \\
\hline $\begin{array}{l}\text { Age, yr, mean } \pm \text { SD } \\
(n=1519)\end{array}$ & - & $28.8 \pm 4.1$ & $31.2 \pm 4.3$ & $31.8 \pm 4.4$ & $31.2 \pm 4.4$ & \\
\hline Parity & & & & & & 0.077 \\
\hline 0 & $827(53.7)$ & $30(3.6)$ & $563(68.1)$ & $155(18.7)$ & $79(9.6)$ & \\
\hline 1 & $539(35.0)$ & $18(3.3)$ & $333(61.8)$ & $128(23.7)$ & $60(11.1)$ & \\
\hline$\geq 2$ & $151(9.8)$ & $5(3.3)$ & $87(57.6)$ & $42(27.8)$ & $17(11.3)$ & \\
\hline Unknown & $24(1.6)$ & $5(20.8)$ & $11(45.8)$ & $3(12.5)$ & $5(20.8)$ & \\
\hline Marital status & & & & & & 0.115 \\
\hline Married/common-law & $1460(94.7)$ & $49(3.4)$ & $948(64.9)$ & $315(21.6)$ & $148(10.1)$ & \\
\hline Divorced/separated/single & $59(3.8)$ & $5(8.5)$ & $37(62.7)$ & $9(15.3)$ & $8(13.6)$ & \\
\hline Unknown & $22(1.4)$ & $4(18.2)$ & $9(40.9)$ & $4(18.2)$ & $5(22.7)$ & \\
\hline Ethnicity & & & & & & 0.002 \\
\hline Asian & $176(11.4)$ & $8(4.5)$ & $133(75.6)$ & $28(15.9)$ & $7(4.0)$ & \\
\hline White & $1241(80.5)$ & $38(3.1)$ & $794(64.0)$ & $275(22.2)$ & $134(10.8)$ & \\
\hline Other & $94(6.1)$ & $7(7.4)$ & $54(57.4)$ & $19(20.2)$ & $14(14.9)$ & \\
\hline Unknown & $30(1.9)$ & $5(16.7)$ & $13(43.3)$ & $6(20.0)$ & $6(20.0)$ & \\
\hline Family income, \$ & & & & & & 0.152 \\
\hline$<70000$ & $325(21.1)$ & $16(4.9)$ & $200(61.5)$ & $68(20.9)$ & $41(12.6)$ & \\
\hline$\geq 70000$ & $1178(76.4)$ & $36(3.1)$ & $774(65.7)$ & $253(21.4)$ & $115(9.8)$ & \\
\hline Unknown & $38(2.5)$ & $6(15.8)$ & $20(52.6)$ & $7(18.4)$ & $5(13.2)$ & \\
\hline Education & & & & & & $<0.001$ \\
\hline $\begin{array}{l}\text { High school diploma or } \\
\text { lower }\end{array}$ & $164(10.6)$ & $9(5.5)$ & $92(56.1)$ & $31(18.9)$ & $32(19.5)$ & \\
\hline $\begin{array}{l}\text { Completed trade/technical } \\
\text { school }\end{array}$ & $286(18.6)$ & $8(2.8)$ & $162(56.6)$ & $77(26.9)$ & 39 (13.6) & \\
\hline Completed university & $704(45.7)$ & $23(3.3)$ & $465(66.1)$ & $156(22.2)$ & $60(8.5)$ & \\
\hline $\begin{array}{l}\text { Completed postgraduate } \\
\text { degree }\end{array}$ & $354(23.0)$ & $12(3.4)$ & $262(74.0)$ & $56(15.8)$ & $24(6.8)$ & \\
\hline Unknown & $33(2.1)$ & $6(18.2)$ & $13(39.4)$ & $8(24.2)$ & $6(18.2)$ & \\
\hline $\begin{array}{l}\text { Note: } \mathrm{BMI}=\text { body mass index. } \\
\text { *Unless stated otherwise. } \\
\text { †Proportions are row proportions. } \\
\mp \chi^{2} \text { test. }\end{array}$ & & & & & & \\
\hline
\end{tabular}




\section{Underweight}

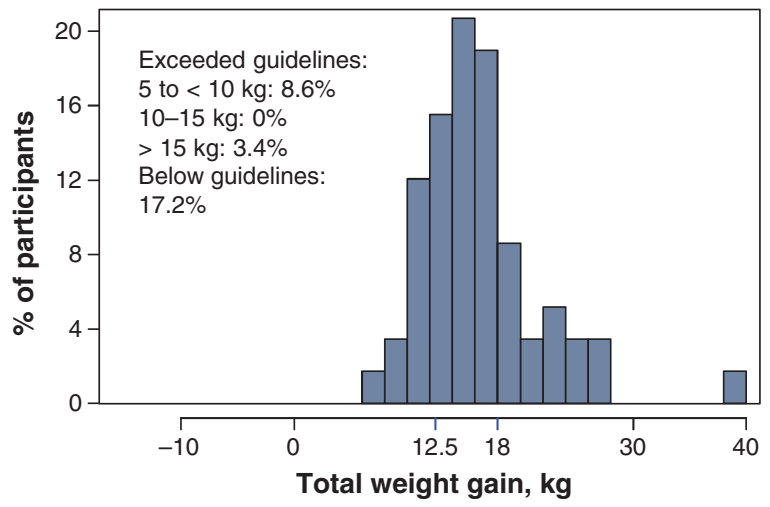

Overweight

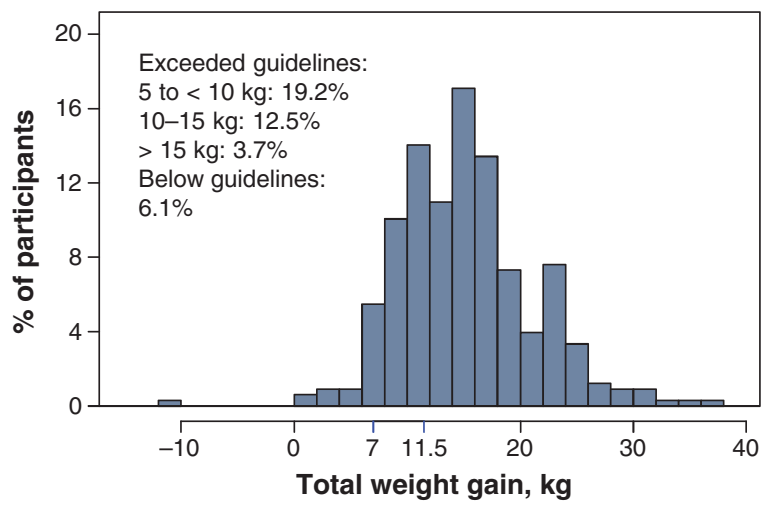

Normal weight

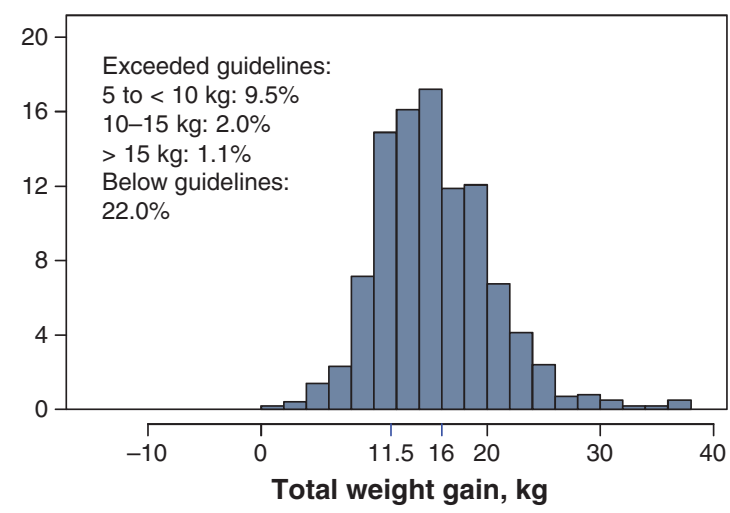

Obese

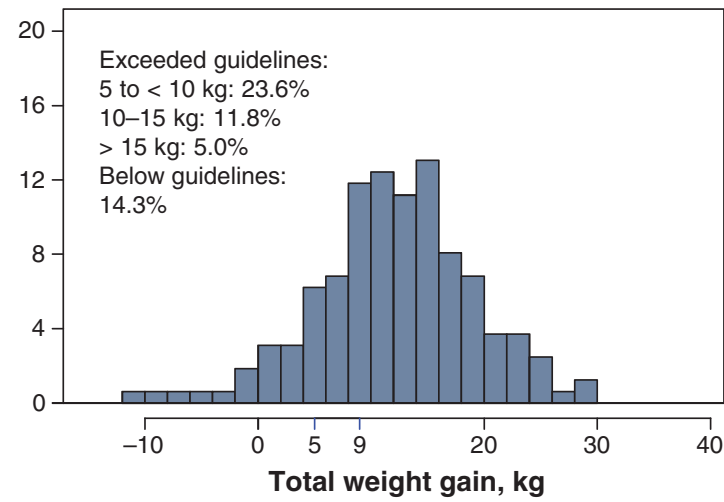

Figure 1: Total gestational weight gain by prepregnancy body mass index category among participants in the Alberta Pregnancy Outcomes and Nutrition (APrON) study. Total weight gain is shown in 2-kg blocks. The blue ticks on the $\mathrm{x}$ axis indicate the recommended lower and upper limits for total weight gain according to Health Canada's guidelines.

shoulder dystocia ${ }^{25}$ in addition to increased risk of overweight in childhood. ${ }^{26-28}$ Similarly, we observed that relatively high proportions of underweight participants and those of normal weight gained less weight than recommended, which is associated with increased risk of a small-for-gestational-age infant. ${ }^{2}$ It is not known whether the risks or the consequences of inadequate weight gain during pregnancy differ by prepregnancy BMI. It is possible that there were clinical explanations for some of the observed excessive or inadequate weight gain among our participants; however, because this was an observational study it was not our objective to explore clinical underpinnings. More research in this area is warranted.

About one-third of participants with a prepregnancy BMI in the overweight or obese category had an average weekly rate of weight gain in the second and third trimesters that was more than double the recommended upper limit. Rapid rates of weight gain during the second and third trimesters are well documented, ${ }^{29,30}$ although factors contributing to the high rates observed in our study are not well understood. The fact that most participants in the normal, overweight and obese groups exceeded the recommended weekly rates of weight gain suggests that rapid weight gain is not well attended to by health care providers or women during this phase of pregnancy.

Historically, a sigmoidal pattern of gestational weight gain has been commonly described, with weight gain accelerating between the second and third trimesters and plateauing in late pregnancy $y^{6,31}$ as fetal growth slows in the final weeks of gestation. ${ }^{32}$ More recent evidence, including that from the current study, suggests that, in many women, weight may continue to increase up until delivery. ${ }^{33,34}$ High rates of weight gain in the second and third trimesters have been associated with larger gains in maternal fat mass, higher birth weight and longer birth length. ${ }^{35,36}$

\section{Limitations}

A limitation of our study was that we calculated prepregnancy BMI using self-reported prepregnancy weight; however, sensitivity analyses suggested that the data were reasonably accurate. Furthermore, more than $10 \%$ of participants categorized as being of normal weight or overweight when self-reported 

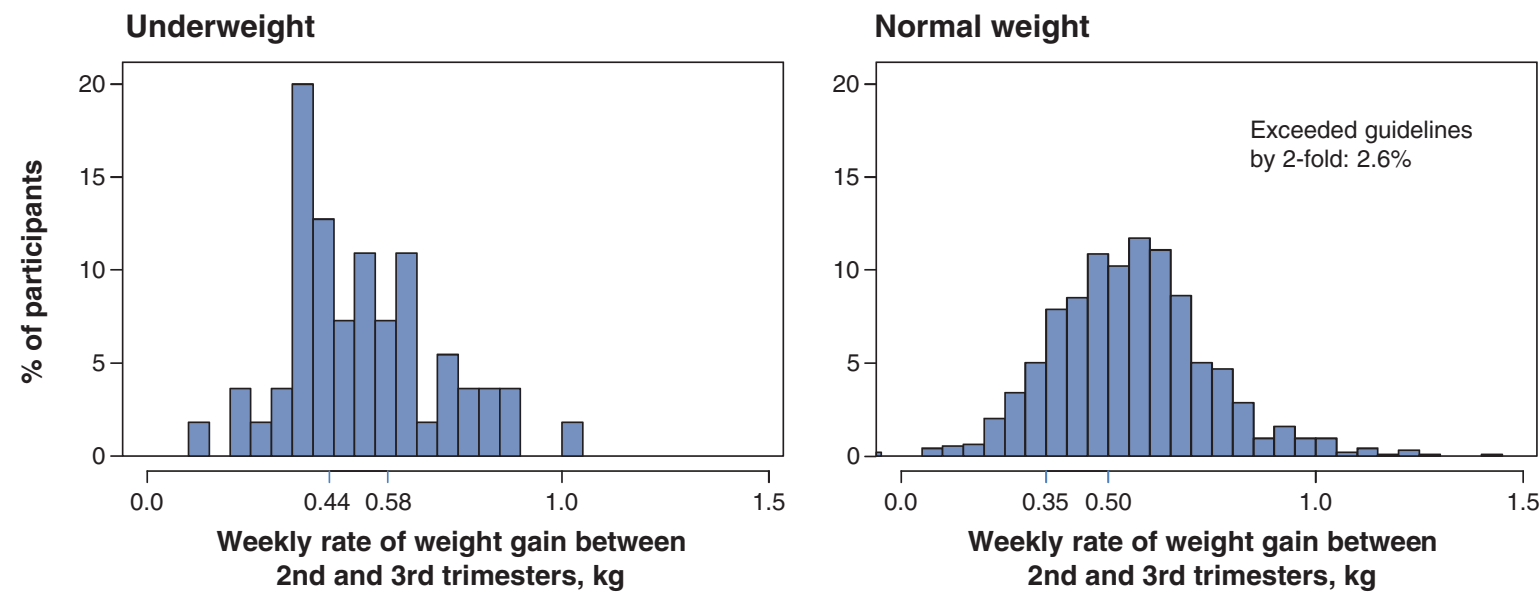

\section{Overweight}

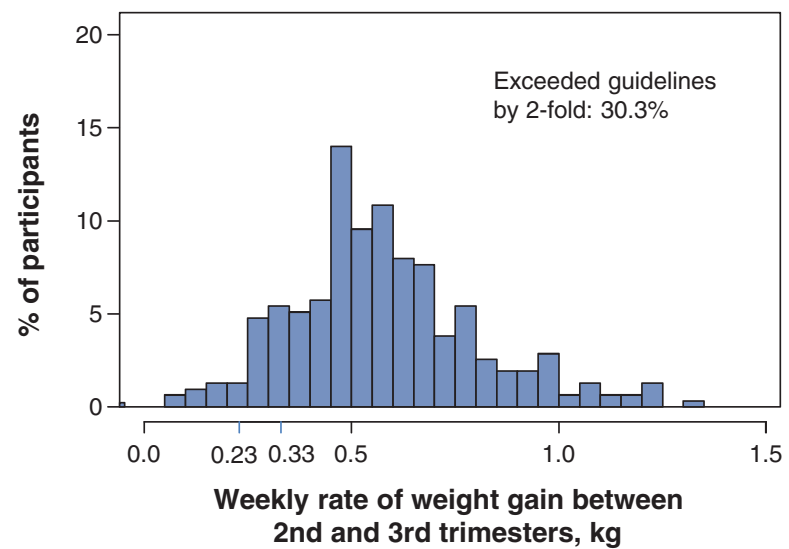

Obese

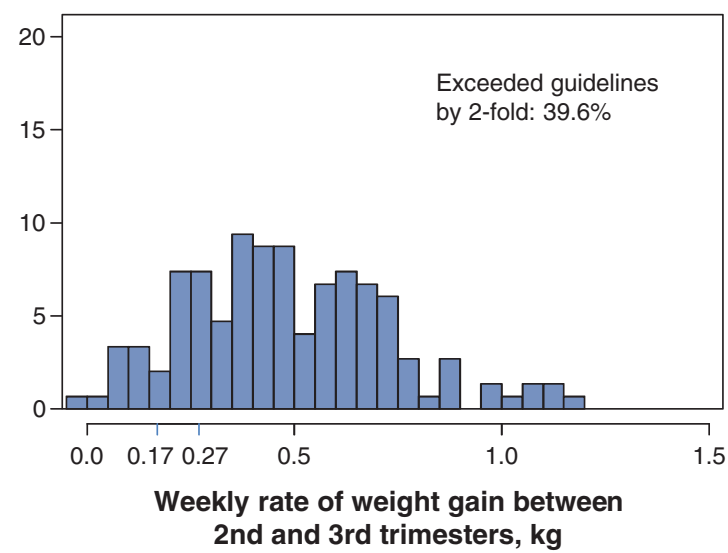

Figure 2: Weekly rate of weight gain between the second and third trimesters by prepregnancy body mass index category among participants in the Alberta Pregnancy Outcomes and Nutrition study. The rate of weight gain is shown in $0.05-\mathrm{kg}$ blocks. The blue ticks on the $\mathrm{x}$ axis indicate the recommended lower and upper limits for weekly rate of weight gain according to Health Canada's guidelines.

weight was used to derive BMI actually belonged to the nexthigher weight category. In addition, self-reported highest weight during pregnancy was missing for 307 participants, and we used their measured weight in the third trimester as a substitute. We carried out sensitivity analysis and a simulation study to investigate the implications of these procedures. The results indicated that the proportions of participants who exceeded recommendations for both total and rate of weight gain increased in all 4 prepregnancy BMI categories, which suggests that our results appear to be conservative estimates of the true proportions of participants with excessive gestational weight gain.

Compared with women of childbearing age in a representative nationwide survey of Canadians, ${ }^{37}$ a greater proportion of our participants had higher levels of education and household income. Because APrON is a prospective cohort study, it was not designed to be representative of all Canadian women of childbearing age. Higher education has been shown to be associated with better adherence to guidelines for gestational weight gain. ${ }^{38}$ Thus, it is likely that adherence to these guide- lines in the general Canadian population of childbearing women is poorer than what we report here.

\section{Conclusion}

Our findings in this group of highly educated woman and adolescent girls suggest that weight management in pregnancy is challenging and complex and that the scope of the issue is likely to be much larger than reported here. Nonetheless, our observations reinforce Health Canada's recommendations ${ }^{7}$ that gestational weight gain be discussed with all pregnant patients, irrespective of prepregnancy BMI category, and that messages may need to be tailored for those in different prepregnancy BMI categories. Our observations also suggest that these conversations need to be held early in pregnancy, when it is more feasible to provide support that may mitigate the risk of excessive or inadequate weight gain. Consideration of the average weekly rate of weight gain may be particularly important for health care providers. The rate of gestational weight gain reflects the likely trajectory of total weight gain during the pregnancy and may provide a tool to 


\section{Normal weight before pregnancy}

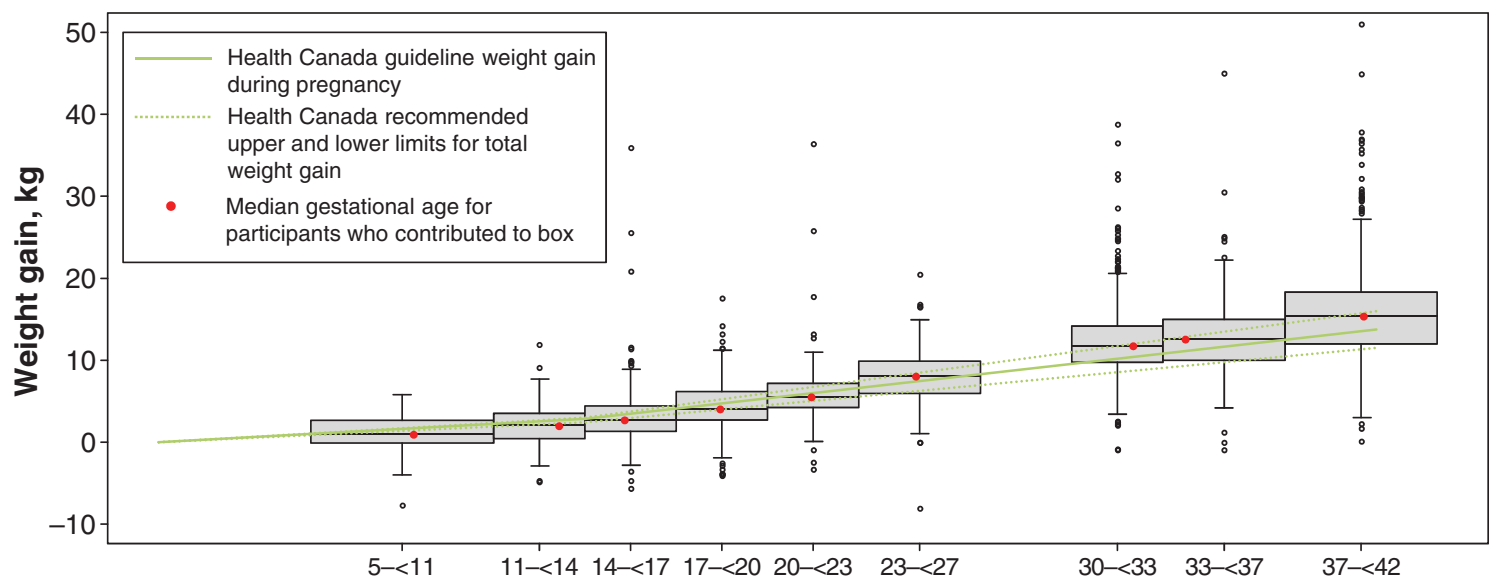

Overweight before pregnancy

Duration of pregnancy, wk

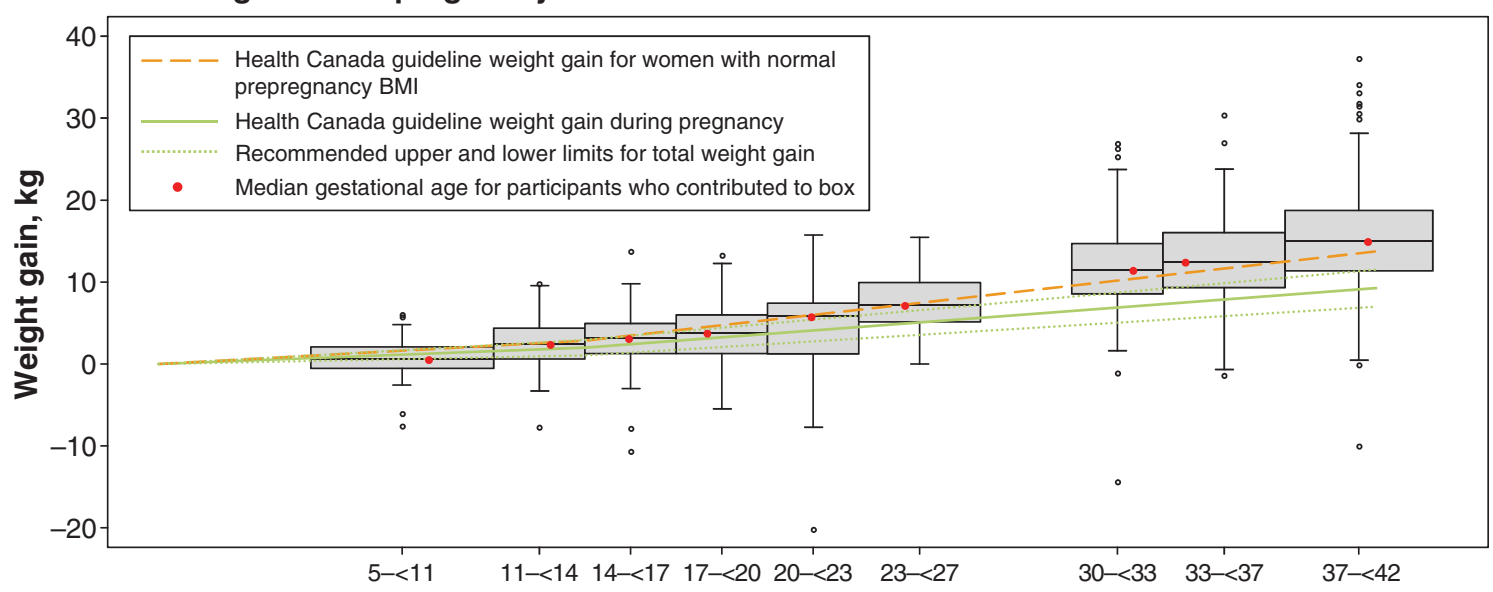

Obese before pregnancy

Duration of pregnancy, wk

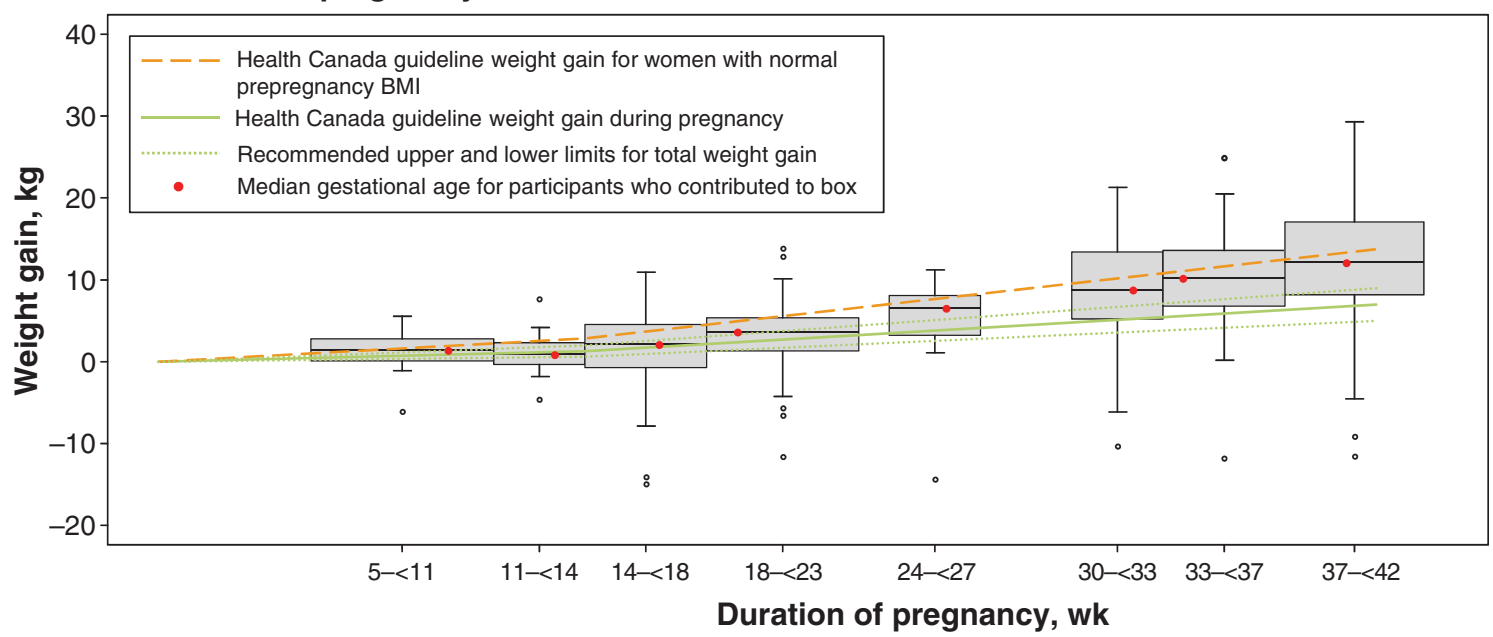

Figure 3: Box plots of the median and interquartile range of weight gain at each measurement time point according to prepregnancy body mass index (BMI) category. Participants were included in 2 or 3 boxes each according to how many study visits they attended. The box plot for the underweight category is not shown because of the small sample size $(n=58)$. 
identify and provide additional support for women at risk of not meeting weight gain guidelines. More research is needed to explore how to address the issue of gestational weight gain, particularly in the context of the Canadian health care system.

\section{References}

1. Davis RR, Hofferth SL, Shenassa ED. Gestational weight gain and risk of infant death in the United States. Am 7 Public Health 2014;104(Suppl 1):S90-5.

2. Stotland NE, Cheng YW, Hopkins LM, et al. Gestational weight gain and adverse neonatal outcome among term infants. Obstet Gynecol 2006;108:635-43.

3. Nehring I, Schmoll S, Beyerlein A, et al. Gestational weight gain and longterm postpartum weight retention: a meta-analysis. Am 7 Clin Nutr 2011;94: 1225-31.

4. Johnson J, Clifton RG, Roberts JM, et al. Pregnancy outcomes with weight gain above or below the 2009 Institute of Medicine guidelines. Obstet Gynecol 2013;121:969-75

5. Nohr EA, Vaeth M, Baker JL, et al. Combined associations of prepregnancy body mass index and gestational weight gain with the outcome of pregnancy. Am 7 Clin Nutr 2008;87:1750-9.

6. Institute of Medicine. Weight gain during pregnancy: reexamining the guidelines. Washington: National Academies Press; 2009.

7. Prenatal nutrition guidelines for health professionals: gestational weight gain. Cat no 978-1-100-16831-9. Ottawa: Health Canada; 2014. Available: www.hc-sc. gc.ca/fn-an/nutrition/prenatal/ewba-mbsa-eng.php (accessed 2016 May 13).

8. Weisman CS, Hillemeier MM, Downs DS, et al. Preconception predictors of weight gain during pregnancy: prospective findings from the Central Pennsylvania Women's Health Study. Womens Health Issues 2010;20:126-32.

9. Melzer K, Schutz Y. Pre-pregnancy and pregnancy predictors of obesity. Int 7 Obes (Lond) 2010;34(Suppl 2):S44-52.

10. Lowell H, Miller DC. Weight gain during pregnancy: adherence to Health Canada's guidelines. Health Rep 2010;21:31-6.

11. Begum F, Colman I, McCargar LJ, et al. Gestational weight gain and early postpartum weight retention in a prospective cohort of Albertan women. 7 Obstet Gynaecol Can 2012;34:637-47.

12. Deputy NP, Sharma AJ, Kim SY, et al. Prevalence and characteristics associated with gestational weight gain adequacy. Obstet Gynecol 2015;125:773-81.

13. Liu J, Gallagher AE, Carta CM, et al. Racial differences in gestational weight gain and pregnancy-related hypertension. Ann Epidemiol 2014;24:441-7.

14. Kaplan BJ, Giesbrecht GF, Leung BM, et al. The Alberta Pregnancy Outcomes and Nutrition (APrON) cohort study: rationale and methods. Matern Child Nutr 2014;10:44-60.

15. Manca DP, O'Beirne M, Lightbody T, et al. The most effective strategy for recruiting a pregnancy cohort: a tale of two cities. BMC Pregnancy Childbirth 2013;13:75.

16. Winkvist A, Brantsaeter AL, Brandhagen M, et al. Maternal prepregnant body mass index and gestational weight gain are associated with initiation and duration of breastfeeding among Norwegian mothers. 7 Nutr 2015;145:1263-70.

17. Dudenhausen JW, Grunebaum A, Kirschner W. Prepregnancy body weight and gestational weight gain - recommendations and reality in the USA and in Germany. Am 7 Obstet Gynecol 2015;213:591-2.

18. Harris DE, Aboueissa AM, Baugh N, et al. 11-year trends in pregnancy-related health indicators in Maine, 2000-2010. F Pregnancy 2014;2014:780626.

19. Cheikh Ismail L, Bishop DC, Pang R, et al. Gestational weight gain standards based on women enrolled in the Fetal Growth Longitudinal Study of the INTERGROWTH-21st Project: a prospective longitudinal cohort study. BM7 2016;352:1555.

20. Kapadia MZ, Park CK, Beyene J, et al. Weight loss instead of weight gain within the guidelines in obese women during pregnancy: a systematic review and meta-analyses of maternal and infant outcomes. PLoS One 2015;10: e0132650.

21. Ferraro ZM, Qiu Q, Gruslin A, et al. Excessive gestational weight gain and obesity contribute to altered expression of maternal insulin-like growth factor binding protein-3. Int 7 Womens Health 2013;5:657-65.

22. Camacho-Buenrostro D, Perez-Molina JJ, Vasquez-Garibay EM, et al. The association between pre-pregnancy obesity and weight gain in pregnancy, with growth deviations in newborns. Nutr Hosp 2015;32:124-9.

23. Kim SY, Sharma AJ, Sappenfield W, et al. Association of maternal body mass index, excessive weight gain, and gestational diabetes mellitus with large-forgestational-age births. Obstet Gynecol 2014;123:737-44.
24. Black MH, Sacks DA, Xiang AH, et al. The relative contribution of prepregnancy overweight and obesity, gestational weight gain, and IADPSG-defined gestational diabetes mellitus to fetal overgrowth. Diabetes Care 2013;36:56-62.

25. Weissmann-Brenner A, Simchen MJ, Zilberberg E, et al. Maternal and neonatal outcomes of large for gestational age pregnancies. Acta Obstet Gynecol Scand 2012;91:844-9.

26. Dietz $W$. How to tackle the problem early? The role of education in the prevention of obesity. Int 7 Obes Relat Metab Disord 1999;23(Suppl 4):S7-9.

27. Dietz WH, Nelson A. Barriers to the treatment of childhood obesity: a call to action. 7 Pediatr 1999;134:535-6.

28. Boney CM, Verma A, Tucker R, et al. Metabolic syndrome in childhood: association with birth weight, maternal obesity, and gestational diabetes mellitus. Pediatrics 2005;115:e290-6.

29. Hinkle SN, Johns AM, Albert PS, et al. Longitudinal changes in gestational weight gain and the association with intrauterine fetal growth. Eur 7 Obstet Gynecol Reprod Biol 2015;190:41-7.

30. Walter JR, Perng W, Kleinman KP, et al. Associations of trimester-specific gestational weight gain with maternal adiposity and systolic blood pressure at 3 and 7 years postpartum. Am 7 Obstet Gynecol 2015;212:499.e1-12.

31. Hytten F. Clinical physiology in obstetrics. Oxford: Blackwell Scientific Publications; 1991.

32. Hytten F. Weight gain in pregnancy. Oxford: Blackwell Scientific Publications; 1980.

33. Carmichael S, Abrams B, Selvin S. The pattern of maternal weight gain in women with good pregnancy outcomes. Am 7 Public Health 1997;87:1984-8.

34. Villamor E, Gofin R, Adler B. Maternal anthropometry and pregnancy outcome among Jerusalem women. Ann Hum Biol 1998;25:331-43.

35. Widen EM, Factor-Litvak PR, Gallagher D, et al. The pattern of gestational weight gain is associated with changes in maternal body composition and neonatal size. Matern Child Health 7 2015;19:2286-94.

36. Karachaliou M, Georgiou V, Roumeliotaki T, et al. Association of trimesterspecific gestational weight gain with fetal growth, offspring obesity, and cardiometabolic traits in early childhood. Am 7 Obstet Gynecol 2015;212:502.e1-14.

37. Urquia ML, O'Campo PJ, Ray JG. Marital status, duration of cohabitation, and psychosocial well-being among childbearing women: a Canadian nationwide survey. Am 7 Public Health 2013;103:e8-15.

38. Brawarsky P, Stotland NE, Jackson RA, et al. Pre-pregnancy and pregnancyrelated factors and the risk of excessive or inadequate gestational weight gain. Int 7 Gynaecol Obstet 2005;91:125-31.

Affiliations: Department of Agricultural, Food and Nutritional Science (Jarman, Pakseresht, Robson, Bell) and School of Public Health (Yuan, Shi), University of Alberta; Cancer Measurement, Outcomes, Research and Evaluation (C-MORE) (Robson), Cancer Control Alberta, Alberta Health Services, Edmonton, Alta.

Contributors: Megan Jarman and Yan Yuan are joint first authors. Rhonda Bell acquired the data, and Megan Jarman and Yan Yuan drafted the manuscript. All of the authors contributed substantially to study conception and design, and data analysis and interpretation, revised the manuscript for important intellectual content, approved the final version submitted for publication and agreed to act as guarantors of the work.

Funding: The Alberta Pregnancy Outcomes and Nutrition (APrON) study was funded by Alberta Innovates - Health Solutions. Analyses reported in this manuscript were also funded by Alberta Innovates Health Solutions through a Collaborative Research Innovation Opportunities Program Grant awarded to Rhonda Bell, Paula Robson and the ENRICH study team.

Acknowledgements: The authors acknowledge Fatheema Begum Subhan, Sarah Loehr, Anne Gilbert, Ala Qabaja, Andrea Deane and Lubna Anis for their assistance with data collection and database development. The authors are sincerely grateful to all APrON study participants and team members.

Supplemental information: For reviewer comments and the original submission of this manuscript, please see www.cmajopen.ca/content/4/2/ E338/suppl/DC1 